\title{
MICRO-CONFLICTOS ESPACIALES Y HABITUS POLÍTICO DE LOS GRUPOS CONTRA-HEGEMÓNICOS
}

\section{SPATIAL MICRO-CONFLICTS AND POLITIC HABITUS OF THE COUNTERHEGEMONIC GROUPS}

\author{
Adolfo García Jerez \\ Universidad Pablo de Olavide, Sevilla
}

\begin{abstract}
Resumen.- El objetivo de este artículo ${ }^{1}$ radica en el interés por describir, analizar y explicar la praxis que se activa en el proceso de construcción social de aquellos lugares en los que se ha suscitado un conflicto; indagar sobre cuál es el habitus de los grupos contra-hegemónicos que participan en ellos y las condiciones estructurales y valores dominantes en los que los conflictos se producen. Todo ello a través de un trabajo etnográfico de cinco años sobre el centro histórico de la ciudad española de Sevilla.
\end{abstract}

Palabras claves.- espacio-contestado, conflicto urbano, movimientos sociales, prácticas políticas, procesos de enmarcamiento, ethos hedonista

Abstract.- The objective of this article is to describe, to analyze, and to explain the praxis generated during the social construction process of contested-spaces; to investigate the habitus of contra-hegemonic groups participing in them, and to analyze structural conditions and the dominant values in which the conflicts are produced. All this is done through a case study of the historic center of Spanish city of Seville, where I conducted ethnografic research for five years.

Key words.- contested-space, urban conflict, social movements, political practices, framing process, hedonistic ethos

\section{A modo de introducción}

Cualquier tránsito por la trama urbana de cualquier ciudad puede suponer el descubrimiento de eventos y acciones políticos imprevistos. De hecho en la topografía urbana hay lugares en los que la ciudadanía siente predilección a la hora de mostrar alguna denuncia o reclamación en el orden de lo público: mineros que acampados en la principal plaza durante varias jornadas reivindican mejoras laborales; concentraciones y procesiones civiles que se adentran por las arterias vertebradoras de una urbe reclamando a la administración mejores prestaciones; pequeños grupos de jóvenes que al tiempo que rodean un edificio intentan demorar, al menos, su inminente desalojo; o asociaciones de vecinos que movilizados demandan la conservación de un parque próximo.

\footnotetext{
${ }^{1}$ Este artículo es producto de una investigación financiada por la Consejería de Innovación, Ciencia y Empresa de la Junta de Andalucía dentro del programa de Formación de Personal Docente e Investigador (FPDI) para un periodo de 4 años (2003-2007).
} 
Bien es cierto que en todos estos ejemplos podemos distinguir la existencia de un conflicto social y su plasmación en un espacio. Sin embargo, si agudizamos nuestra mirada podemos observar algunas diferencias ontológicas relevantes: mientras en los dos primeros el uso del espacio sirve para acomodar las demandas enunciadas, en los dos restantes el espacio se convierte en el objeto y en el medio de lo demandado. Estos últimos, por tanto, en nuestra opinión, son los fenómenos sociales cuya naturaleza posibilitaría que fuesen calificados con el término de espacios-contestados (Low 2003, Herzog 2004, Schmelzkopf 1995), en tanto que para que se produzca un fenómeno englobado en esa categoría, al menos, se debe producir un conflicto entre diferentes agentes y, lo que es más importante, que la simiente de este conflicto, su motivo estructurante sea el control en todas sus dimensiones (producción, construcción y uso) de un espacio por parte de esos mismos agentes sociales. Sin embargo, no toda controversia o disputa espacial ha de ser considerada conflicto. Por conflicto, entonces, entenderemos -siguiendo las apreciaciones de Ágnes Heller- "...las formas de aquellas fricciones cotidianas en las que también pueden estar presentes los afectos y los intereses particulares, pero cuya motivación principal viene dada por valores genéricos y principalmente morales" (Heller 2002: 649-650). A diferencia de otros fenómenos análogos como el de la disputa en el conflicto sí se generará un profundo debate: moral contra moral, concepción del mundo contra concepción del mundo, nos dirá Heller.

Cierto es que dentro de la literatura sociológica se han ido elaborando teorías sobre la existencia de estos grupos contra-hegemonicos, entendiéndolos como aquellas configuraciónes sociales básicas que muy frecuentemente consituyen, y dan sentido a, los Movimientos Sociales. De hecho, fueron Charles Tilly (2009) y Sydney Tarrow (2004) quienes desde la Sociología y las Ciencias Políticas elaboraron una primera teoría, denominada "Teoría del Sistema de Oportunidades", que apostaba por analizar las prácticas y valores de estos y de otros grupos teniendo en consideración los márgenes que ofrece el sistema para participar políticamente y la relación que se establecía entre ese sistema y los Movimientos Sociales. Sin embargo, autores como McCarthy y Zald (1977), sin desdeñar dicha propuesta, viraron el ángulo de análisis y se interrogaron sobre las formas de articulación, trabajo y activación de los recursos que poseían estas agrupaciones sociales en relación al conflicto, entendiendo que las infraestructuras organizativas, así como la relación existente entre la forma organizativa, el tipo de movimiento y la influencia que ejercen sobre ellos tanto las estructuras estatales como el tipo de "cultura organizativa" de una sociedad (McAdam et. al., 1999) condicionaban la constitución y capacidad de los Movimientos Sociales. A esta perspectiva se la denominó "Teoría de las Estructuras de Movilización". Empero, aún quedaba por dilucidar cómo un colectivo construye la realidad en clave conflictiva. Fueron Robert Brenford y David Snow (2000) quienes se encargaron de explicarlo a través de la "Teoría de los Procesos de Enmarcamiento" y la existencia de varios marcos que posibilitan dicha construcción social. En concreto, hablaban de tres marcos: el de "diagnostico", cuya función es la de identificar un acontecimiento como problemático y susceptible de cambio, así como situar a los grupos en los roles de oponentes, protagonistas y audiencias; el "marco de pronóstico", siendo su objetivo el de elaborar una estrategia para enmendar la situación problemática; y el de "motivación", el cual implica la elaboración de razonamientos que justificaran esas mismas prácticas. 
De este modo, oportunidades de participación, organización social y percepción de la realidad se han ido imbrincando en el análisis de los grupos contrahegemónicos, y por extensión de los Movimientos Sociales, a fin de describir y explicar las prácticas, las visiones y consecuencias de sus iniciativas.

Así pues, partiendo de estas teorías, y muy especial de la "Teoría de los Procesos de Enmarcamiento", y del concepto de conflicto de Agnes Heller, el presente artículo $^{2}$ trata de reflexionar sobre cuáles son los resortes y mecanismos en forma de discursos como en forma de prácticas son activados por los grupos contrahegemónicos con el objeto de transmutar un lugar hasta entonces sentido de un modo apacible -o, al menos, flemático-, a otro con una clara connotación conflictual. Resortes y mecanismos que inexcusablemente nos conduce al habitus político (Bourdieu 1997) de estas agrupaciones sociales.

\section{Condiciones estructurales y valores dominantes}

Partimos de la premisa de que las condiciones estructurales y los valores dominantes son factores externos que condicionan el habitus de aquellos individuos que deciden participar en un conflicto espacial, es decir, en los modos en que estos perciben y practican la realidad. Pero, ¿cuáles son esas condiciones estructurales?

En nuestra opinión, la precariedad laboral y la presión inmobiliaria se nos muestran como dos de los factores actuales más destacables para las sociedades tardo-capitalistas. Con respeto a la primera, ésta podría resumirse por un fuerte desempleo, que para el caso español en el último lustro ha alcazado el 20\%; o, en su defecto, un acceso irregular al mercado laboral a través de contratos temporales y la obtención de bajos ingresos económicos (Lapuente y Ortiz de Villacian 2000). Mientras que en relación a la presión inmobiliaria, sus contingencias estarían definidas por un acceso restringido al mercado habitacional como consecuencia de los altos alquileres y de la dificultades materiales de adquirir una vivienda en régimen de propiedad (Taller contra la Violencia Inmobiliaria y Urbanística 2006), así como la sobredificación urbana, provocando la disminución o pérdida de autonomía e independencia personal, especialmente para una mayoría de los jóvenes.

De este modo, la importancia de estas condiciones estructurales y sus efectos no sólo devienen porque en los últimos años se hayan convertido en unas de las principales fuentes de conflictos (Aguilar y Fernández 2010), sino también porque han contribuido y mucho a la configuración del habitus de muchos sectores de la sociedad, en especial el de aquellos que forman parte de los grupos contrahegemónicos. Habitus político que que podría ser definido, entre otras cuestiones, por un sentimiento de recelo y alejamientode hacia aquellas instituciones políticas que han concurrido tradicionalmente en el ámbito laboral (como son los sindicatos y partidos políticos) y la aparición y asimilación, en especial por una pequeña parte de los jóvenes, de una nueva identidad colectiva bajo la categoría de "precario" (Della Porta 2006, Mosca 2006).

\footnotetext{
${ }^{2}$ Este texto es la revisión aumentada y corregida de una ponencia presentada en el X Congreso Español de Sociología celebrado en 2010 en Pamplona (España).
} 
Sin embargo, el habitus de estos grupos, como el de cualquier otro colectivo, no sólo está condicionado por la posición que poseen sus individuos en la estructura social, sino que a su vez está permeabilizado por los valores dominantes de la sociedad de la que también forman parte, si bien, como veremos más adelante, no es óbice para que éstos puedan reconfigurlo y moldearlo en función de sus propios intereses.

Siguiendo el ejercicio de síntesis realizado por Elías Zamora (1999), en nuestra opinión la sociedad posmoderna se caracteriza por un rapidísimo ritmo de cambio que afecta muy profusamente a las representaciones que se hacen de la realidad, en cuanto que éstas quedan muy rápidamente obsoletas, o como dice dicho autor, "el mundo o la sociedad son construidos siempre en el pasado" (Zamora 1999: 11); pero también por un proceso paradójico de mundialización y fragmentación que si, de un lado, significa una cierta homogeneización cultural, del otro, supone el "desarrollo extremo de los individualismos", la consagración del individuo y su centralidad, así como la constitución de nuevas identidades en base a nuevas maneras de sociabilidad que tratan de superar esa fragmentación e individualización. A esto habría que sumar una cierta tendencia conductiva hacia el "presentismo" y el "hedonismo", es decir, hacia la idea de vivir la vida ahora y del modo más lúdico e indoloro posible. Tendencia que no sólo se manifiesta en el terreno psico-social con la aparición de un "ethos hedonista" (Lipovetsky 1987) basado en la búsqueda del placer individual (Jameson 1991), sino también en el terreno político (Bauman 2001, Barriga 1993) con el desmonte y la pérdida referencial de los grandes relatos políticos construidos a finales del siglo XIX y principios del XX.

Así pues, estos son los valores dominante que, pensamos, junto a las condiciones estructurales han repercutido en la forma de percibir y practicar, de entre otras cuestiones, lo político en el contexto en el que se desenvuelven nuestros espacios y gupos contra-hegemónicos. Forma cuya extrapolación al campo de lo político se resumiría en los siguientes aspectos: (1) Un desinterés por la política institucional, como así lo demostraban los datos del Centro de Estudios Sociológicos recogidos en el Barómetro de Abril de 2007, en los que los encuestados asociaban fundamentalmente a la palabra "poítica" con "desconfianza" e "indiferencia"; (2) y una baja participación dentro del asociacionismo formal de tipo político, según la encuesta en esta ocasión elaborada por el Centro de Estudios Andaluces (incluida en el estudio titulado "Clases sociales y estructura social" de la Consejería de Presidencia de la Junta de Andalucía, 2005), que en relación a la pertenencia a grupos o asociaciones en Andalucía, los agrupamientos que poseían un mayor porcentaje de socios eran los sindicatos, con un 8'5\%; seguidos de las asociaciones de apoyo social o de derechos humanos, con un 6\%; y en último lugar, con sólo 4'9\%, los partidos políticos.

Por tanto, esa baja presencia en agrupamientos con un carácter político explícito y la concepción tan negativa que envuelve a este campo confirman el desinterés por parte de sectores amplios de la sociedad española, y en particular de la andaluza, con respecto a la política institucional. Tendencia que podría estar estrechamente relacionada tanto con la desacreditación inducida por la política profesional como por esas condiciones sociales que caracterizan a nuestra sociedad donde el individuo, como ya expusimos, se repliega sobre sí mismo y sobre estilos de vida basados en el "presentismo" y en el "hedonismo", por lo que valores 
fundamentados en el "compromiso" y en el "sacrificio" no son sentidos como los más deseables.

Si este sistema de valores lo trasladásemos al campo de lo político, y en particular a las acciones de los grupos-contra-hegemónicos, podría plantearse a modo de hipótesis, entonces, que las principales prácticas colectivas empleadas serían aquellas en las que ni se exigen mucho esfuerzo ni continuidad en su realización y donde lo festivo jugaría un rol básico.

\section{Un esbozo de trayectoria espacial}

A fin de encontrar algunas claves para entender mejor la génesis y los motivos de la aparición de los espacios-contestados seleccionados, y tal y como nos sugiere Loïc Wacquant (2007), es necesario en una primera instancia analizar los fenómenos históricos espaciales de la zona donde se localizan esos mismos lugares en tanto que estos procesos nos proveerán de explicaciones con las que dar respuesta a la existencia de los espacios-contestados. De este modo focalizaremos nuestra atención en la parte norte del centro histórico de Sevilla $^{3}$, así como en tres fenómenos urbanos.

El primero de ellos tuvo lugar a mitad del siglo XIX cuando se localizaron pequeñas industrias en la parte noreste del casco antiguo, lo que conllevó que esa zona se caracterizara por su composición obrera y popular (Almedo 1995). Como prueba de ello debemos aludir a la todavía permanencia en activo de algunos de esos enclaves industriales y artesanales tales como los del Pasaje Mallol, el de la plaza del Pelícano y los de la calle Castellar 48, 50 y 52 con Dueñas.

El segundo de los procesos urbanos nos conduce a la obsolescencia física y social que culminó en la década de los 70 del siglo XX con la transformación de este área en un nudo de mercadeo, consumo de estupefacientes y prostitución. Así lo demuestró el estudio titulado "Urban San Luís-Alameda" elaborado en el año 1994 por el Ayuntamiento de Sevilla, en donde se contabilizó alrededor de 20 prostíbulos y de 1000 personas que vivían de dicha actividad; así como 300 drogadictos y 20 espacios donde se consumía habitualmente droga, lo que motivó que en la década de los 90 localizaran en una de las plazas existentes, la del Pumarejo, un ambulatorio perteneciente al gobierno regional que desde entonces se encargaría de dispensar metadona, un comedor benéfico en una calle próxima a dicha plaza, así como un albergue para indigentes gestionado por el ayuntamiento. Junto a este declive social hay que sumar el mal estado de conservación y el de ruina de muchos inmuebles de la zona. Sólo en el año 2005 se contabilizaron un total de 82 infraviviendas y 500 edificios en mal estado (Correo de Andalucía, 03-10-2005). Fenómeno de obsolescencia física que en vez de reconducirse hacia el mejoramiento de las condiciones de vida de los inquilinos mediante la aplicación efectiva de programas de rehabilitación tales como el Plan Urban (de 1995 a 1999) o el Área de Rehabilitación Concertada San Julián-San Luís-Alameda (desde 2003), éstos se mostraron ineficaces (Díaz 2009; García

\footnotetext{
3 Ciudad que se encuentra localizada geográficamente al sur de España. Es la capital administrativa de la Comunidad Autónoma de Andalucía. Cuenta con una población de 705.200 habitantes; su centro histórico es uno de los más extensos de España (con 3,2 Km2), uno de los más poblados (con 56.733 habitantes) y uno de los primeros en ser declarado conjunto patrimonial.
} 
1998) puesto que no pudieron detener la expulsión que venía produciéndose desde el año 1991 -ya que al menos fueron expulsados alrededor de 3500 inquilinos de corrales y patios de vecinos localizados en el centro de la ciudad y sus arrabales, según las estimaciones realizadas por Fernández (2003)-. O una vez que estos programas se aplicaron, paradójicamente, aceleraron ese proceso de "gentrificación" (Díaz 2008), es decir, el proceso mediante el cual se consuma el recambio poblacional de un área (Smith 1996). Ante tal despropósito y drama social el ayuntamiento no tuvo más remedio que constituir en el 2005 una oficina encargada de asesorar a esos mismos inquilinos.

$Y$ un tercero nos remite a la colonización territorial, puesto que ese proceso de obsolescencia física y social ocasionó que durante este intervalo de tiempo comenzaran a rondar por esta zona individuos pertenecientes a un sector joven (estudiantes y artistas) que deseosos por encontrar pisos y naves a precio módico decidieron asentarse en esta zona, puesto que era el área que mejor satisfacía sus necesidades debido a las facilidades residenciales que ofrecía, así como su inmejorable localización geográfica al estar en pleno centro de la ciudad y próxima a diversas facultades universitarias. Asimismo, miembros de otros sectores comenzaron a residir en estos barrios, especialmente nuevos vecinos con otro perfil caracterizados por poseer formación universitaria, de entre 30 y 45 años y con más poder adquisitivo (Boletín Demográfico de Sevilla 2005). Junto a ellos, a partir del año 2000, hay que mencionar la llegada de algunos colectivos compuesto en su mayoría por jóvenes, quienes empezaron a replegarse por esta zona ocupando locales y naves industriales en desuso y abandonados con el fin de dotarla de actividades. Estos grupos contra-hegemónicos se caracterizaban por una práctica espacial de carácter conflictual basada en la crítica contra la especulación y la gentrificación.

En nuestra opinión estos tres fenómenos gestaron un contexto social y espacial propicio para la génesis de múltiples espacios-contestados en un territorio relativamente pequeño como era el de la parte norte del centro histórico de Sevilla y en un intervalo de tiempo no excesivamente largo, hablamos de una década desde 1998 a 2008-. El Centro Social Okupado Casas Viejas (Adell 2004), el conflicto en torno al mercado de la Encarnación (Moreno 2005) o el de de la Alameda de Hércules (García 2009a; 2009b) fueron ejemplos de ellos, pero también otros como la casa-palacio Pumarejo, la huerta del Rey Moro y el corral de artesanos de la calle Castilla. Estos últimos, como consecuencia de su riqueza y matices, se han convertido en objetos y protagonistas de nuestro análisis.

\section{Etnografía de los espacios-contestados}

De este modo, centrándonos en el primero de ellos, enfrente de la plaza de Pumarejo, en su flanco oeste, es donde se encuentra la casa-palacio de mismo nombre. Un caserón edificado en el siglo XVIII de dos plantas de 1200 metros cuadrados de superficie estructurado en dos patios interiores, en la que la primera se encuentran las dependencias dedicadas a locales mientras que en la segunda se localizan las viviendas. Edificio que a los largo de su vida ha sido usado sucesivamente a modo de palacete, de prisión en tiempos de los franceses, escuela, biblioteca de adultos y viviendas arrendadas. Tras algunas ventas en 1975 la casa fue heredada por cuatro hermanos en régimen de herencia de tipo 
indivisa. Será a partir de entonces cuando dio comienzo la decadencia del inmueble debido a la desidia de sus propietarios al no acometer ninguna reforma con la que hacer frente al deterioro existente y no arrendando las dependencias que quedaban vacías. Al deterioro físico se le sumó el vaciamiento social al permanecer sólo una decena de familias. Situación que se agravó a finales de los 90 del siglo XX con la compra del $50 \%$ del inmueble por una firma hotelera, lo que generó una honda preocupación por el destino final de dicho inmueble tanto en las familias que aún residían en el palacio como en determinados grupos asentados en el barrio. Este fue el motivo para que en el año 2000 se estableciesen los primeros contactos entre un grupo de jóvenes quienes formaban parte de colectivos ecologistas, pacifistas y "okupas" y algunos de los inquilinos residentes (Hernández 2003).

De este modo, a partir de esos primeros contactos se constituyó la Plataforma por la defensa de la Casa-Pumarejo (alrededor de 15 personas) que, gracias a la organización de las primeras acciones (desde el 21 de marzo de 2000), llevó a cabo un proceso de resimbolización de la finca, el cual produjo la puesta en circulación de tres imágenes espaciales a veces de forma escalonada, otras de forma simultánea.

Una primera imagen que hablaba de la casa-palacio como un símbolo de lucha y resistencia en contra de la especulación urbanística y, por tanto, por el derecho a la permanencia de los inquilinos de "renta antigua", es decir aquellos cuyo contrato de arrendamiento era anterior a 1984. Esta idea (la de la anti-especulación) configuró un "marco de motivación" basado en la denuncia pública de la pasividad de la administración frente al fenómeno de gentrificación y del reconocimiento del derecho de estos inquilinos a permanecer en sus viviendas en contra fundamentalmente de los intereses de la empresa hotelera, propietaria de la mitad del edificio.

La segunda imagen hablaba de un inmueble con valor patrimonial. Un significado estrechamente ligado a la llegada de varios expertos al grupo (en especial de un antropólogo), quienes generaron un cambio en cuanto al "marco de pronóstico" y a su idea-fuerte, puesto que si todavía el argumento contra la especulación y su resistencia era importante, a ésta se le sumó ese nueva imagen que hablaba de este inmueble desde su valor patrimonial, lo que quedó sintetizado en la siguiente eslogan: Casa de Pumarejo: Patrimonio vivo del Barrio. Con ello se buscaba remarcar ese componente patrimonial que señalaba que los inquilinos y el propio edificio configuraban un ecosistema que debía ser conservado, pues representaba el primero un singular modo de vida y el segundo una tipología residencial tradicional. Por consiguiente, ambos susceptibles de ser protegidos. Y para ello invocaron a la Ley Andaluza sobre Patrimonio y en especial a la inscripción de Bien de Interés Cultural (BIC), puesto que ésta hacía mención del valor patrimonial no sólo de los bienes materiales a conservar sino también de los etnológicos, incluídas las formas de vida genuinas. Se ha de recordar que uno de los objetivo que persigue dicha ley es el de afianzar la conciencia de identidad andaluza a través de la investigación, difusión y conocimiento de los valores históricos, culturales y lingüísticos del pueblo andaluz en toda su riqueza y variedad. En cualquier caso, esta ampliación de las ideas-fuertes supuso cambios en el marco de "pronóstico", puesto que ya no sólo se debía luchar en el ámbito de lo jurídico sino también -y de forma prioritaria- se debía trazar una estrategia que favoreciera 
su reconocimiento administrativo como BIC. Era necesario, entonces, ganar cierta legitimidad social que permitiese negociar dicho estatus con la administración, de ahí que urgiera constituir un nuevo "marco de motivación" con el que alcanzar dicho reconocimiento patrimonial.

Una vez conseguido que la administración catalogara la casa de BIC instaron a ésta a que obligara a la propietaria del inmueble a acometer las reformas para su conservación o, en su defecto, iniciara la expropiación del edificio. Tras comprobar la lentitud de la administración en acometer tales medidas, la Plataforma por la defensa del Pumarejo puso en circulación una tercera imagen que apuntaba al valor social de la casa que quedó sintetizada en otro eslogan que rezaba lo siguiente: El Centro Vecinal Pumarejo: Espacio recuperado por y para el barrio. Éste aludía a la constitución y apertura en el año 2005, en una de las dependencia de la casa-palacio, de un centro social autogestionado cuya función era la de dinamizar esa zona de la ciudad, además de proseguir con las demandas sobre la propia finca. De este modo, la Plataforma en defensa de la Casa Pumarejo junto con otros grupos y colectivos sociales reclamaron a la administración no sólo el derecho de permanencia de los inquilinos de "renta antigua" y lo que conllevaba la catalogación del inmueble de BIC, sino también el derecho de respeto a un nuevo espacio que funcionaba con otra "lógica" (Cruces y Díaz de Rada 1996), es decir, con un modo de pensar y actuar propio y diametralmente diferente al de los demás. Nueva lógica basada, en esta ocasión, en lo autogestionado, en lo social y en lo creativo.

Con respecto al segundo ejemplo etnográfico, la huerta del Rey Moro, señalar que éste era un espacio cuyo tamaño alcanzaba aproximadamente los 5.500 metros cuadrado. Porción de tierra que se encontraba inserto entre dos calles de la parte noreste del casco antiguo: las llamadas calle Enladrillada en su flanco oeste y calle Sol al este, allí donde tambien se hallaba ubicado un palacete mudéjar. Este conjunto formado por el palacio y su entorno más inmediato fue declarado Bien de Interés Cultural (BIC) bajo la categoría de Monumento ${ }^{4}$ en el 2001. Sin embargo, lo que otrora fue huerta devino en un solar cercado y abandonado por la administración cuya intención, expresada en el nuevo Plan General de Ordenación Urbana (PGOU) del 2006, era fundamentalmente la de edificar parte del mismo con viviendas de protección oficial.

Fue en el año 2002 cuando dos vecinas (pertenecientes a grupos y colectivos contra-hegemónicos) otearon por primera vez el solar y rápidamente mediante unas octavillas invitaron a grupos cercanos a visitarlo (Bárber et al. 2006). De forma muy espontánea, con muy pocos medios y sin disponer aún de una estrategia elaborada, se fue constituyendo una cuadrilla que además de formar parte de redes amicales sus miembros poseían un habitus político similar. Cuadrilla que estaría conformada por un grupo pequeño de jóvenes vecinos con experiencias en otras movilizaciones localizadas en espacios próximos -tales como la Alameda de Hércules, la casa-palacio Pumarejo y el Centro Okupado Casas Viejas-, muchos de ellos universitarios e insertos de un modo precario en el mundo laboral. Muy pronto se autodenominaron Los Amigos de la Huerta del Rey Moro. A veces funcionaba a modo de cuadrilla, en los que los lazos amicales eran los que vinculaban a sus escasos 4 ó 5 miembros, otras como un cuasi-grupo -es

\footnotetext{
${ }^{4}$ Decreto 121/2001 de 22 de mayo de 2001 (Boja núm. 78, de 10 de julio de 2001).
} 
decir, aquella configuración social basada en la existencia de un núcleo reconocido y reconocible sobre el que pivota otros afines-. Por supuesto siempre informal, sin ser una entidad registrada ni, por tanto, reconocida por la administración, y cuya forma de organización interna se basaba en lo asambleario y la asunción de funciones voluntaria donde el liderazgo casi siempre recaía en el núcleo inicial.

En cualquier caso, uno de los aspectos que hay que subrayar es la capacidad de este pequeño grupo de vecinos de articular una micro-red que les permitió plantear un conflicto, así como resignificar y dotar de sociabilidad a un, hasta entonces, "no-lugar" (Augé, 1998), es decir un espacio incapaz de generar identificación e interacciones sociales. De este modo los contactos cara a cara, los lazos amicales y la vertebración a microescala de aquellos agrupamientos sociales existentes en el barrio dieron como fruto algunas acciones conjuntas entre los denominados Los amigos de la Huerta del Rey Moro y grupos tales como la Asociación de Vecinos de San Julián, la asociación de padres y madres de los Altos Colegios y Ecologistas en Acción, más la inserción de otros colectivos cuya localización hasta entonces no se encontraban en el propio barrio como era el caso de Ecolocal: un agrupamiento constituido por una decena de jóvenes universitarios cuyo interés recaía en la educación medioambiental.

Con respecto a la primera idea la huerta se presentaba bajo dos consideraciones. De un lado, sobre la base de sus potencialidades se proyectaba una imagen de que era posible hacer algo impensable hasta ahora (una huerta) y que había un lugar cerca de para ello. Un descubrimiento presentando como deseable y deseado por y para el barrio. Para corroborar que esto tenía precedente se señalaba a los casos de Miraflores y San Jerónimo, en tanto éstos se habían convertido en unas de las primeras y más exitosas experiencias en Sevilla de ocupación y constitución de huertos urbanos llevadas a cabo por vecinos (Carmona, J. 2004). De otro, se apuntaba a los beneficios sociales de su posible presencia, puesto que aquello podía funcionar como un espacio de sociabilidad. También se incluía alusiones a la "amenazadora" posibilidad de que el ayuntamiento construyera algunas viviendas y edificios.

Ahora bien la huerta, y cómo ésta se presentó, se vio implementada con otras imágenes como fue la de la vecindad y su participación. Tan necesario era su recuperación en forma de huerta cultivable y multifuncional como la de su administración. Desde su comienzo se concibió como una oportunidad de autogestión de un espacio y sus usos por parte de un ente abstracto denominado vecindad. Con ello se buscaba entrelazar a los vecinos con la existencia de unas necesidades determinadas vinculadas con las zonas verdes que el barrio por su densidad edificada no las podía ofrecer de modo eficiente. La puesta en circulación de carteles y folletos dirigidos a ese genérico denominado vecindad sirvió para, de un lado, dar a conocer mínimamente un espacio definido bajo la categoría de huerta o jardín (aunque con escaso éxito, puesto que en estos primeros meses de 2002 sólo el marco de "diagnóstico" alcanzó a los círculos más próximos) y, del otro, unos posibles usos muy específicos así como bajo una gestión igual de especial. Sin embaro, en el 2004 la cuadrilla organizó una conferencia arqueológica. El objetivo era comenzar a otorgarle "valor patrimonial con la participación de los vecinos", es decir, la intención evidente era la de resemantizar al espacio, la de concebirlo más allá de un solar. Ello requería activar 
un mecanismo de puesta en circulación de imágenes de ese lugar que supusiera una determinada política administrativa que obligara al consistorio y a otras administraciones a retractarse de su intención edificadora, además de suscitar más interés en una posible audiencia. Y qué mejor, pensaron, que utilizar a modo de capital el componente patrimonial y el carácter histórico y social del que el espacio estaba acreditado. Imágenes que hablaba de la huerta como de un jardín precolombino (sic), una huerta para la vecinos y un espacio de sociabilidad para el barrio. Ahora bien, esas imágenes no se consificaron sólo verbalizándolas, sino que fueron producidas mediante la puesta en marcha de pequeñas acciones tales como los encuentros informales, la visita al lugar a partir de actividades comensales y festivas o el reparto de folletos informativos. Prácticas que tenían como fin, y utilizando las nociones de Berger y Luckmann (1993), el de institucionalizar, objetivizar e interiorizar esas imágenes y significados por un agrupamiento mayor con el objeto de que, sobre esa idea del espacio, ese conglomerado social legitimara una serie de iniciativas, reclamara unas determinadas políticas y criticaran otras que habían sido enunciadas desde la administración. Para ello era necesaria la activación de un determinado conjunto de acciones que cumplieran con esas funciones.

Y en relación al tercero de los espacios seleccionados -el corral de artesanos de la calle Castellar- éste era un espacio de 3.000 metros cuadrados de uso productivo de titularidad privada en el que se ubicaban, además de un colegio privado y unas cuantas cocheras, unas decenas de talleres de artesanos no muy bien conservados. Así quedó recogido en las fichas del PGOU de 2006 cuando hablaban de este enclave como de un espacio obsoleto y no funcional. Interpretación nada baladí, pues con ella se justificaba e impulsaba el traslado de esos talleres juntos con otros a lo que se denominó "Polígono Sacro". Un proyecto de polígono de 20.000 metros cuadrados situado entre las barriadas periféricas de Pino Montano y San Jerónimo, cuyo objetivo era mejorar y modernizar las instalaciones que giraban en torno a la actividad del arte religioso en la ciudad de Sevilla. Asimismo, junto a este traslado se planeaba constituir un nuevo enclave en la calle San Luís número 70 -próximo, por tanto, a la calle Castellar-, previsto de 25 viviendas de protección oficial en régimen de alquiler, 20 talleres y 55 aparcamientos (07-11-2007, 20minutos). Sin embargo, muy al contrario de lo que podría pensarse, frente a esas proyecciones un grupo de artesanos y artistas mostraron su rechazo.

De este modo, tratando de no homogeneizar este gremio, debido a que en su interior coexistían desde viejos artesanos del "arte sacro" hasta jóvenes artistas, se ha de subrayar la existencia de al menos dos posiciones: la de aquellos que cuestionaban las actuaciones previstas y la de aquellos otros que las sancionaban positivamente, ya que la invitación por parte de la administración local, en la figura del departamento municipal Sevilla Global, de trasladar la producción artesanal relacionada con el "arte sacro" a las afueras de la ciudad fue apoyada por un sector de los artesanos que trabajaban allí y, con ellos, una de sus asociaciones más importantes. Sin embargo, para un grupo de jóvenes artesanos y artistas que llevaban algunos años trabajando en ese enclave ese proyecto se concebía de forma negativa, pues en su opinión ese traslado restaría socio-biodiversidad al barrio. Además de que, y quizás esto es lo más importante, este proyecto no les garantizaba un espacio donde seguir trabajando, según lo que dedujeron de la 
exposición pública del Plan General de Ordenación Urbana (PGOU) a finales de febrero de 2006. Un conflicto que nos recuerda al del barrio barcelonés de Poblenou, ya que sus espacios fabriles fueron igualmente objeto de una polémica reconversión urbanística por parte de la adminsitración, lo que suscitó una muy fuerte opisición tanto por parte de los vecinos como de sus usuarios (Capel 2007).

De este modo, el aviso y la constatación de que durante los meses posteriores a su exposición pública del PGOU se estaban produciéndose cambios en él que afectaban al porvenir del corral funcionaron a modo de amenaza, provocando que un grupo de artesanos y artistas comenzasen a reunirse bajo la denominación de Plataforma de Artesanos del Casco Antiguo (PACA) con el fin de articular una estrategia para la movilización. Muchos de ellos tenían experiencias en conflictos suscitados en algún espacio del centro histórico de la ciudad (García 2009b), de ahí se explica que su habitus, configurado por disposiciones aprehendidas durante esos años de conflicto, les orientase dentro del campo político hacia unas determinadas visiones y prácticas coincidentes con las de otros espacios y conflictos anteriormente tratados y que atravesaban cuestiones relacionadas con el ecologismo, el pacifismo, la "okupación" y cierta conducta comunitarista a la vez que hedonista (Maffesoli 1990). Orientaciones que formaban parte de una especie de trayectoria social o, tal y como lo denomina Bourdieu (citado en Gutiérrez 2002), de su "historia hecha cuerpo", y que influirá y mucho en la percepción y la práctica que tienen en relación al espacio y su tratamiento. Este habitus, basado en lo conflictual, lo asambleario y lo informal, al mismo tiempo que cohesionaba al grupo lo alejaba de algunos de aquellos atersanos vinculados al "mundo cofrade", que si bien mostraban cierto recelo a las iniciativas proyectadas por la adminístración, no se caracterizaban abiertamente por una conducta beligerante.

\section{Prácticas colectivas en la simbolización del espacio}

Sin embargo, detectar la existencia de estos conflictos espaciales no nos suministra información suficiente para entender cómo y a través de qué mecanismos se han generado esos espacios-contestados. En todo caso sólo nos alumbra sobre cuáles son las percepciones que poseen diversos agentes en relación con un lugar en el cual se ha originado un conflicto. Es por ello que estimemos pertinente que el etnólogo esté in situ en el propio desarrollo de esa contienda y aplique lo que la antropóloga noteaméricana Setha Low denomina la "observational methodologies" (2005) para, de este modo, contrastar desde la experiencia etnográfica aspectos referidos a la real naturaleza de la disputa, la composición de los agentes que intervienen -en esta ocasión los grupos contrahegemónicos- y los discursos y prácticas que son activados en la defensa de los intereses de esos mismos agentes, cuyo fin último, recordemos, es transformar un lugar hasta entonces velado, incluso repudiado, en un espacio-contestado.

En todos los casos analizados fueron cuadrillas o camarillas las que iniciaron ese proceso de simbolización espacial en clave conflictual, realizándolo a partir de interacciones sociales que a medida que se intensificaban iban aumentando su grado de formalidad. Estas acciones, que englobaría reuniones y asambleas consumándose una vez por semana o quincenalmente ${ }^{5}$-, contribuyen, en nuestra

${ }^{5}$ Esto supone un ratio aproximado de 36 reuniones o asambleas anuales para las semanales - 
opinión, a institucionalizar unas ideas-fuertes para que éstas sean posteriormente externalizadas, objetivizadas e interiorizadas tanto por individuos y grupos afines e iguales como por una futura audiencia. De este modo, en esos primeros encuentros se definía: (1) la problemática (la expulsión de los vecinos en relación a la Casa Pumarejo o el desmantelamiento de unos corrales de artesanos en la calle Castellar; así como la posible pérdida de una huerta en el centro de la ciudad como consecuencia de su edificación). (2) Pero también los oponentes (las empresas privadas propietarias de los espacios y, en especial, la administración) y se atisbaban las primeras soluciones tal como la expropiación de la casa-palacio del Pumarejo y del Corral de la calle Castellar o la anulación de los proyectos de edificación en la Huerta del Rey Moro. (3) Junto a la definición de la problemática y de los oponentes se comenzaba a delimitar un "nosotros", una identidad colectiva que les permitiese adquirir, entre otras cuestiones, una "identidad pública" (Laraña y Gusfield 2001) con la que presentarse y ser presentado a una audiencia. Esto se consumó en el momento en que se consensuaba una denominación para el grupo, como las de la Plataforma por la defensa de la Casa Pumarejo, la Plataforma de Artesanos del Casco Antiguo (PACA) y la de los Amigos de la Huerta del Rey Moro.

En definitiva, con esas primigenias interacciones, y utilizando las categorías dadas por David Snow y Robert Benford (1992; 2000), se estaba constituyendo "el marco de diagnóstico" imprescindible para todo agente social en tanto que con él se define y se alienta a la acción colectiva. Una vez formulado el diagnóstico se elabora una estrategia con la que revertir la situación y unas argumentaciones que las sustenten, y conforme a ellas se marca un ciclo de protesta (Tarrow, 2004). Es lo que se denomina el "marco de pronóstico" y el "marco de motivación". El objetivo básico de esa estrategia, como explicamos al principo de este artículo, es la de poner en circulación la problemática localizada en ese espacio y las justificaciones que han de servir para legitimar públicamente su proyecto espacial en relación tanto con los oponentes como con la audiencia a la cual se dirigen.

De este modo, en aras de analizar las acciones comunes que se llevaron a cabo con ese fin, y aún a riesgo de simplificar la realidad social, las hemos encuadrado en tres tipos de prácticas: las sociales, las lúdicas y las eminentemente políticas.

(1) Las prácticas sociales podrían definirse como aquellas acciones que, si bien forman parte del campo de lo político, obedecen sobre todo a la articulación de los marcos tanto de "pronóstico" como de "motivación", no siendo presentadas ni como políticas ni lúdicas. Algunas de las más activadas fueron: (a) Las llamadas Jornadas o mesas redondas: son conferencias organizadas por los diferentes agentes cuyo eje temático refiere al propio espacio. Para ello se suele convocar a otros colectivos con experiencias similares para que expongan su caso a modo de referencia, así como a expertos que además de trasmitir conocimiento específico contribuyan a apuntalar el "marco de motivación", como así se consumaron en los casos analizados. (b) Las rutas guiadas: consisten en que un miembro del grupo o colectivo explica a una pequeña audiencia de proximidad (compuesta de iguales y afín) la problemática del espacio, así como su valor social no reconocido, todo ello

como las convocadas por la Plataforma por la Defensa del Palacio Pumarejo-, ó 18 para las quincenales -tal que las celebradas por los Amigos de la Huerta del Rey Moro-. En el recuento de los meses se han excluido los de Julio, Agosto y Diciembre al ser los principales meses de "asueto" de estos grupos. 
contextualizándolo con el acceso directo al espacio y por medio de referencias históricas, lo que contribuye a dotar de mayor credibilidad a la demanda. Frecuentemente esa ruta ensambla otros lugares, lo que permite ir tejiendo una red de espacios afectados y grupos afines. En todos los ejemplos presentados se consumaron en varias ocasiones. (c) Y, por último, la elaboración de informes: en especial destacan aquellos cuya función a veces es la de servir como simiente de una posible catalogación patrimonial beneficiosa para con los intereses de los grupos que se encuentran peor posicionado en la campo de lo político, lo que les apremia a dominar conocimiento y lenguaje técnico-administrativo. Es una técnica que funciona a modo de disposición aprendida y que se transmite entre los propios grupos. En nuestra etnografía los informes más destacados fueron los realizados por la Plataforma en defensa de la Casa del Pumarejo y el elaborado por la PACA con respecto a los corrales de artesanos ubicados en el casco antiguo sevillano.

En total, sumando los diferentes espacios-contestados, y para el periodo de 20032008, se llevaron a cabo aproximadamente 5 jornadas, 11 rutas y 2 informes patrimoniales.

(2) Las prácticas lúdicas son aquellas acciones que se presentan bajo el prisma de lo festivo, si bien sirven para reforzar esos procesos de enmarcamiento, para alinearlos y poner en circulación unas determinadas imágenes espaciales y grupales. Ejemplos de ellos serían: (a) las iniciativas comensales: son almuerzos colectivos consumados en un ambiente distendido e informal y llevados a cabo en el propio espacio con el fin de cimentar el uso del mismo -siempre y cuando el lugar lo permita- y transmitir, aunque sea de un modo discontinuo, la problemática del espacio; y (b) las fiestas: acción que otorga al tiempo y al lugar una dimensión especial pudiendo dotar a este último de un carácter de "hierofanía" (Eliade 2003), es decir, de un halo cuasi sagrado capaz de convertir al espacio en una de las referencias básicas del grupo. En ocasiones, para esas acciones festivas se utilizan los formatos de aquellas otras que se encuentran entroncadas con la cultura tradicional local -como son, para el caso de Sevilla, la Semana Santa y las Cruces de Mayo-, lo que permite depositar sobre los espacios donde acontecen un prurito aún más señero, debido a que esas fiestas refuerzan la imagen de estos lugares de ser espacios vinculándolos a la tradición y a lo popular.

Entre iniciativas comensales y fiestas tenemos contancias de que durante el periodo de nuestro trabajo de campo, se organizaran alrededor de 27 acciones cuya gestión recayó sobre los grupos implicados directamente en el conflicto espacial. De este modo, no se han tenido presente aquellas otras acciones que, formando parte de estas mismas prácticas, no mantenían un vínculo directo con la problemática espacial.

(3) Y, por último, las prácticas políticas, es decir aquellas acciones cuya naturaleza se fundamenta en inferir en la esfera pública presentándose como tales. En ellas podemos distinguir las institucionales y las no institucionales. Entre las primeras destacan las presentaciones de alegaciones y participación en procesos participativos tutelados por la administración, máxime cuando en la última década en la zona en el cual se ha desarrollado la investigación se han ejecutado al menos cinco procesos participativos gubernamentales (Plan Urban, el Área de Rehabilitación Concertada, la "Alameda que te gusta", "Pumarejo: espacio de convivencia" y el Plan General de Ordenación Urbana). En todos ellos particiapron 
miembros de los colectivos estudiados. Mientras que en las segundas, las no institucionales, podríamos aludir a las ruedas de prensa y, en especial, a las "performances" públicas en las que un pequeño grupo a través de una acción vistosa, pacífica y mediática denuncia o reclama una serie de consideraciones con respecto al lugar objeto de conflicto.

Con respecto a las ruedas de prensa, sólo tenemos constancia de la realización de una para el intervalo 2003-2008, mientras que en relación a las performances, y para ese mismo periodo, se contabilizaron 8.

Cuadro 1. Síntesis aproximativa de Practicas Colectivas ${ }^{6}$.

\begin{tabular}{|c|c|c|c|c|c|}
\hline \multicolumn{2}{|c|}{ Prácticas Sociales } & \multicolumn{2}{|l|}{ Prácticas Lúdicas } & \multicolumn{2}{|l|}{ Prácticas Políticas } \\
\hline \multirow[t]{2}{*}{ Jornadas } & \multirow[t]{2}{*}{5} & \multirow{4}{*}{$\begin{array}{l}\text { Iniciativas } \\
\text { Comensales y } \\
\text { Fiestas }\end{array}$} & \multirow[t]{4}{*}{27} & $\begin{array}{l}\text { Procesos } \\
\text { Participativos } \\
\text { Institucionales }\end{array}$ & \multirow[t]{2}{*}{5} \\
\hline & & & & Ruedas de Prensa & \\
\hline Rutas & 11 & & & Performaces & 8 \\
\hline Informes & 2 & & & & \\
\hline $\begin{array}{l}\text { Número de } \\
\text { acciones }\end{array}$ & Total: 18 & & Total: 27 & 6 & Total: 14 \\
\hline $\begin{array}{l}\text { Prácticas } \\
\text { con una } \\
\text { fuerte }\end{array}$ & Rutas & $\begin{array}{l}\text { Iniciativas } \\
\text { Comensales y } \\
\text { Festivas }\end{array}$ & & Performances & \\
\hline festiva & & & & & \\
\hline $\begin{array}{l}\text { Número de } \\
\text { acciones }\end{array}$ & 11 & 27 & & 8 & Total: 46 \\
\hline $\begin{array}{l}\text { Prácticas } \\
\text { con una } \\
\text { débil } \\
\text { dimensión } \\
\text { festiva }\end{array}$ & $\begin{array}{l}\text { Jornadas } \\
\text { e } \\
\text { Informes }\end{array}$ & & & $\begin{array}{l}\text { Procesos } \\
\text { Participativos } \\
\text { Institucionales y } \\
\text { Ruedas de Prensa }\end{array}$ & \\
\hline $\begin{array}{l}\text { Número de } \\
\text { acciones }\end{array}$ & 7 & & & 6 & Total: 13 \\
\hline
\end{tabular}

\section{Habitus político y capital simbólico de los grupos contra-hegemónicos}

Así pues, centrándonos en estos grupos, existía una característica común a todos ellos en relación a la movilización de recursos (McCarthy y Zald 1977) y, sobre todo, a su capital social (Putnam 1995; Jacobs 1961). La mayoría de ellos eran agrupamientos sociales basados en la constitución de un núcleo pequeño de

\footnotetext{
${ }^{6}$ Datos propios obtenidos a partir del trabajo de campo entre 2003 y 2008 y que hacen referencia a las prácticas colectivas cuyo objetivo es el de poner en circulación una imagen conflictual del espacio. Quedan excluidas, por tanto, las prácticas asamblearias.
} 
líderes (cuadrillas y camarillas, según el grado de amistad) que a su alrededor se constituían a veces círculos sociales que podían dar lugar a la conformación de cuasi-grupos. No disponían, por tanto, de otra clase de miembros del estilo de afiliados o socios, si acaso simpatizantes. Característica común tanto para aquellos más informales como para los más formalizados. De este modo, el único instrumento que poseían en cuanto a la movilización de sus recursos humanos era la de activar esa red de grupos afines en los momentos que son percibidos como los más oportunos: una especie de llamada social. Éste era el capital social cuantitativo con el que contaban. Circunstancia que influirá tanto en lo que respecta a las formas y contenidos de las prácticas como en la estrategia a desarrollar. De hecho, este escaso capital social cuantitativo impidió, según nuestra observación, un mejor acceso al capital político puesto que, de un lado, no podían ejercer algunas de las tácticas con las que poner en circulación ese capital social cuantitativo -como la convocatoria de manifestación y huelgas masivas que pudieran cuestionar por ejemplo la formación de gobiernos locales o iniciativas proyectadas a gran escala-; de otro, tampoco les facilitaba el acceso a las "coaliciones de poder". Quizás esta falta de capital social cuantitativo y sus posiciones subalternas dentro del campo político es lo que ha ocasionado que muchos de estos grupos hayan trazado su estrategia en base a la adquisición de capital simbólico con el que al menos poder legitimar sus posiciones sintonizando al mismo tiempo con una audiencia de lejanía.

¿En qué consiste ese capital simbólico?, ¿cómo funciona? En relación a la primera interrogante, por capital simbólico entendemos "...aquella forma que revisten las diferentes especies de capital cuando son percibidas y reconocidas como legítimas" (Bourdieu 2000: 131). De este modo, "el capital simbólico es un crédito, es el poder impartido a aquellos que obtuvieron suficiente reconocimiento para estar en condiciones de imponer el reconocimiento...". Parafraseando a Bourdieu, éste es un poder de hacer cosas con palabras y que, a consecuencia de la pluralidad de visiones sobre el mundo que se da en el contexto social, sirve para, tomando prestadas sus mismas palabras, hacer ver y hacer valer ciertas realidades, y cuya característica, como así también nos advertía Austin (1975), es la de conceder el poder de hacer cosas con palabras. Con respecto a la segunda pregunta, en él podemos diferenciar dos tipos: aquel que funciona para legitimar social e institucionalmente la existencia del propio grupo, de un "nosotros"; y aquella segunda que pudiéndose ser apropiado, acumulado y perdido es el que se obtiene merced a los significados e imágenes con los que se revisten los espacios. Esta forma que adquiere el capital simbólico se nos antoja básica con respecto al "marco de pronóstico", a la movilización de recursos y al poder político.

Si tal y como hemos observado estos grupos no poseían suficiente capital social cuantitativo ni político, entonces uno de los principales recursos para legitimar su posición dentro del campo político era el de dotar al espacio de un significado con el que legitimarse al mismo tiempo que se deslegitima al oponente. El hecho de que un edificio sea concebido como un objeto patrimonializable, y por tanto susceptible de ser catalogado BIC, propicia que un grupo pueda reclamar a la administración que cumpla con su deber, y si ésta no lo hace, sentirse entonces legitimado para llevar a cabo una serie de actuaciones. Es por esto por lo que parte de la estrategia de estos pequeños grupos se ha focalizado en la producción simbólica, en la acumulación de capital simbólico (de legitimidad social e 
institucional tanto del grupo como del espacio) con el objetivo de transformarlo en político para, de este modo, obtener más poder y mejorar su posición dentro del ámbito público, siendo la mejor manera de conseguirlo por medio de aquellas prácticas que combinan los valores basado en el "hedonismo" con un explícito tamiz político. De ahí la inclinación por estos grupos por las acciones bajo un formato lúdico y festero como las prácticas políticas más recurrentes dentro del campo político urbano, haciendo buenas las apreciaciones de Murray Edelman de que "la lógica que explica la atención oficial, pública y de los medios a los problemas políticos no depende de la gravedad de éstos sino de su atractivo dramático..." (Edelman 1991: 36). A fin y al cabo, como nos apunta Francisco Cruces, la consumación de estas prácticas por parte de estos colectivos, tal que “...bailar salsa, agitar banderas o besarse en la calle tal vez no se consideren los modos idóneos de introducir racionalmente asuntos en la agenda política. Mas lo que demuestran tales modos de estar juntos es una gran capacidad para hablar, por medio de imágenes, de aspectos significativos de la experiencia común a los que no llega la jerga de los profesionales de la política" (Cruces 2006: 108). Y si bien la fiesta y ciertos performances festivos han formado históricamente parte de los repertorios clásicos de acción colectiva (Tilly 2009) tales como los sindicatos y partidos políticos (Castells 1986), lo que parece acontecer en estos momentos es una intensificación de lo festivo en la acción política, una carnavalización generalizada que opera también en la mayor parte de las prácticas de protestas de estos grupos contra-hegemónicos, y de lo que el MayDay sólo sería su ejemplo más destacable (Mosca 2006), por cuanto el MayDay, en tanto reinterpretación del Primero de Mayo que tiene lugar en algunas ciudades europea tales como Milán, Londres, Berlín, Barcelona o Sevilla, condensa muchas de las prácticas y significados de estos grupos. Han sido ellos los que durante una semana del mes de Mayo han organizado y llevado a cabo múltiples acciones de protesta con un fuerte carácter festivo, destacando sobre manera las ediciones celebradas en Andalucía (García, 2009b).

\section{A modo de conclusión}

En suma, tal y como hemos planteado con anterioridad, dentro de los ciclos de protestas de estos grupos contra-hegemónicos y de sus repertorios de acción de cara al control de determinados espacios ha aflorado el "ethos hedonista" que caracteriza a la sociedad actual, solo que reelaborado y orientado hacia sus intereses, en tanto que estos grupos y su potencial audiencia no están al margen de esos valores sino que se encuentran al igual que el resto de la sociedad tamizados por estos, al menos parcialmente. Con ello, además de atraer a una posible audiencia por medio de la lógica dominante, han compensado su falta de capital social cuantitativo y su débil posición dentro del campo político con la adquisición de capital simbólico, de ahí que ese capital se haya convertido en uno de los ejes más significativos de su estrategia política dentro, en esta ocasión, de la lucha por el espacio. Un capital simbólico que ha tomado cuerpo en conceptos tales como patrimonio cultural, sociabilidad o participación ciudadana, y que han sido puesto en circulación por los grupos contra-hegemónicos con el fin de aumentar su legitimación social y fomentar el consumo de los nuevos significados 
espaciales entre su posible audiencia. Todo ello de cara a la producción y control de determinados lugares y mediante prácticas de tipo político, social y, muy especialmente, lúdico.

\section{Bibliografía}

(2204) ADELL ARGILÉS, Ramón (coord). ¿Dónde están las llaves?: el movimiento okupa: Prácticas y contextos sociales. Madrid: Los Libros de la Catarata.

(2010) AGUILAR, Susana y Alberto FERNÁNDEZ, "El movimiento por la vivienda digna en España o el porqué del fracaso de una portesta con amplia base social". Revista Internacional de Sociología (RIS), Vol. 68, Septiembre-Dicimebre: 679704.

(1996) ALMUEDO PALMA, José. Ciudad e Industria: Sevilla 1850-1930. Sevilla: Diputación de Sevilla.

(1998) AUGÉ, Marc. Los "no-lugares": espacios del anonimato: una antropología de la sobremodernidad. Barcelona: Gedisa.

(1975) AUSTIN, John Langshaw. How to do things with words. Oxford: Oxford University Express.

(1993) BARRIGA, Silverio. "El individuo en la sociedad del soglo XXI: reflexiones sobre el cambio sociopolítico". Psicotema, 1993, vol. 5 pp 31-43.

(2001) BAUMAN, Zygmunt. La sociedad individualizada. Madrid: Cátedra.

(1993) BERGER, Peter y Thomas LUCKMANN. La construcción social de la realidad. Buenos Aires: Amorrortu.

(2006) BÁRBER, S; FRENSEL, V y ROMERO, M (coords). Como nació, creció y se resiste a ser comido el gran pollo de la Alameda. Una docena de años de lucha social en el barrio de la Alameda.Sevilla. Sevilla: El Gran Pollo de la Alameda.

(1992) BENFORD, Robert y David SNOW. "Master Frames and Cycles of Protest", Pp 133-145 en Frontiers in Social Movement Theory. New Haven: Yale University Press.

(2000) BENFORD, Robert y David SNOW. "Framing processes and social movements: An overview and assessment" en Annual Reviews of Sociology, vol. 26: 11-39.

(1997) BOURDIEU, Pierre. Razones prácticas. Sobre la teoría de la acción. Barcelona: Anagrama. 
(2000) BOURDIEU, Pierre. Cosas dichas. Barcelona: Gedisa.

(2007) CAPEL, Horacio. "El debate sobre la construcción de la ciudad y el llamado 'modelo Barcelona'". Scripta Nova. Revista electrónica de Geografía y Ciencias Sociales, Vol. XI, núm. 233. Consulta el 10 de Febrero de 2011(http://www.ub.edu/geocrit/sn/sn-233.htm).

(2004) CARMONA GALLEGO, José. "Del dicho al hecho... ¿hemos andado ese trecho? Veinte años de lucha ciudadana por el Parque Miraflores", en Democracias participativas e intervención social comunitaria desde Andalucía, editado por Javier Encina et al. (coords) Madrid: ACNUR-Andalucía, Atrapasueños, Junta de Andalucía, Universidad Pablo de Olavide.

(1986) CASTELLS, Manuel. La ciudad y las masas. Sociología de los movimientos sociales urbanos. Madrid: Alianza Universal.

(1996) CRUCES, Francisco y Ángel DÍAZ DE RADA. La ciudad emergente. Transformaciones urbanas, campo político y campo asociativo en un contexto local. Madrid: UNED ediciones.

(2006) CRUCES VILLALOBOS, Francisco. Símbolos en la ciudad. Lecturas de antropología urbana. Madrid: UNED ediciones.

(2008) DÍAZ PARRA, Ibán. "Movimientos vecinales contra la gentrificación y transformaciones en la política local de Sevilla. Los casos de El Pumarejo y San Bernardo", X Coloquio Internacional de Neocrítica. Consulta el 13 de Mayo del 2010 (http://www.ub.edu/geocrit/-xcol/8.htm).

(2009) DÍAZ PARRA, Ibán. "Procesos de revitalización en Sevilla en la coyuntura reciente. Análisis comparado de tres sectores históricos: San Luís-Alameda, Triana y San Bernardo (2000-2006), Scripta Nova, Revista Electrónica de Geografía y Ciencias Sociales, Vol. XIII, No 304. Consulta el 14 de Octubre de 2010 (http://www.ub.edu/geocrit/sn/sn-304.htm\#_edn12).

(2006) DELLA PORTA, Donatella. Social movements: an introduction. Oxford: Blackwell.

(1991) EDELMAN, Murray. La construcción del Espectáculo Político. Buenos Aires: Manantial.

(2003) ELIADE, Mircea. Lo sagrado y lo profano. Barcelona: Paidós.

(2005) MORENO Hernández, Esteban. "La Encarnación, un debate imprescindible". Ben Baso, Boletín № 13, Sevilla.

(2003) FERNÁDEZ SALINAS, Víctor. "Vivienda modesta y patrimonio cultural: los corrales y patios de vecindad en el conjunto histórico de Sevilla" en Scripta Nova. Revista electrónica de Geografía y Ciencias Sociales Vol. VII, núm. 146(070). Consulta el 12 de Agosto del 2010 (http://www.ub.edu/geocrit/sn/sn-146(070).htm).

(1998) GARCÍA JAEN, Josefa. "Aplicaciones de la inciativa comunitaria Urban". Boletín de la A.G.E. № 26-1998: 191-206.

(2009a) GARCÍA JEREZ, F. A. "La Alameda que te gusta. Conflictos Sociales y Planificación Urbana en torno a un Espacio Público". Pp 585-599 en Ciudades globales, culturas locales, editado por Eusko Bilbao, Ikaskuntza.

(2000b) GARCíA JEREZ, F. A. Trazos de la ciudad disidente. Espacios 
contestados, capital simbólico y acción política en el centro histórico de Sevilla. Tesis no publicada, Departamento de Ciencias Sociales, Universidad Pablo de Olavide, Sevilla.

(2002) GUTIÉRREZ, Alicia. Las prácticas sociales: una introducción a Pierre Bourdieu. Madrid: Tierradenadie.

(2003) HERNÁNDEZ RAMÍREZ, Javier. "La construcción social del patrimonio: selección, catalogación e iniciativas para su protección. El caso del Palacio del Pumarejo". Pp 84-95. Antropología y Patrimonio: investigación, documentación e intervención, VV.AA. Sevilla: Conserjería de Cultura, Junta de Andalucía.

(2002) HELLER, Ágnes. Sociología de la vida cotidiana. Barcelona: Península.

(2004) HERZOG, A. Lawrence. "La política, el diseño y el espacio público en la ciudad de México y Barcelona". Pp. 267-303 en Reabrir espacios públicos. Políticas culturales y ciudadana editado por García Canclini. México D.F: Universidad Autónoma Metropolitana,.

(1961) JACOBS, Jane. The Death and Life of Great American Cities. New York: Random Hause.

(1991) JAMESON, Fredic. Ensayo sobre el posmodernismo. Buenos Aires: Imago Mundi.

(2000) LAPUENTE, Jordi y Daniel Ortiz De Villacian. "Las políticas Laborales", en Cambios en el Estado del Bienestar. Políticas sociales y desigualdades en España, editado por J. Adelantado. Barcelona: Icaria,

(2001) LARAÑA, Enrique, y Joseph, Gusfield. Los nuevos movimientos sociales. De la ideología a la identidad. Madrid: CIS.

(1987) LIPOVETSKY, Gilles. La era del vacío. Ensayos sobre el individualismo contemporáneo. Barcelona: Anagrama.

(2005) LOW, Setha. "Rethinking urban parks" en Public Space \& Cultural Diversity, edited by Setha Low. Austin: University of Texas.

(2003) LOW, Setha y Denise LAWRENCE-ZÚÑIGA. The anthropology of space and place: locating culture. Malden: Blackwell.

(1999) MCADAM, Doug et al (edts). Movimientos sociales, perspectivas comparadas: oportunidades políticas, estrucuturas de movilización y marcos interpretativos culturales. Madrid: Istmo.

(1997) MCCARTHY, John D., y MAYER N. Zald. "Resource Mobilization and Social Movements: A Partial Theory". In American Sociologial Review, USA, V. 82, № 6, May: 1212-1241.

(1990) MAFFESOLI, Michel. 1990. El tiempo de las tribus. El declive del individualismo en las sociedades de masa., Bacelona: Icaria.

(2006) MOSCA, Lorenzo. "MayDay parade. Movilizaciones juveniles contra la precariedad laboral". Revista de Estudios Jueventud, diciembre 06, 75: 75-97.

(1995) PUTNAM, R.D. "Bowling alone: America's declining social capital", Journal of Democracy 6 (1), 65-78.

(1995) SCHMELZKOPF, Karen. "Urban community gardens as a contested 
spaced", American Geographical Review 85:3.

(1996) SMITH, Neil. The new urban frontier. Gentrification and revanchist city. New York: Routledge.

(986) Snow, David A. et al. "Frame aligment processes, micromobilization, and movement participation", American Sociological Review, Vol. 51, nº 4.

(2006) Taller contra la Violencia Inmobiliaria y Urbanística. El cielo está enladrillado. Entre el mobbing y la violencia inmobiliaria y urbanística. Barcelona: Edicions Bellaterra.

(2004) TARROW, Sidney. El poder en movimiento. Movimientos Sociales, la Acción Colectiva y la Política. Madrid: Alianza Editorial.

(2009) TILLY, Charles. Los Movimientos Sociales. Barcelona: Crítica.

(2007) WACQUANT, Loïc. Los condenados de la ciudad. Gueto, periferias y Estado. Avellaneda: Siglo XXI Editores.

(1999) ZAMORA ACOSTA. Elías. "Los retos de la posmodernidad: los jóvenes sevillanos ante el nuevo milenio". Pp11-32 en Una nueva cultura para los jóvenes, editado por J. Hurtado. Sevilla: Ayuntamiento de Sevilla, Sevilla. 